\title{
Response entropy as a function of the affective quality of the stimulus'
}

\author{
PHEBE CRAMER ${ }^{2}$ \\ BARNARD COLLEGE, COLUMBIA UNIVERSITY
}

\begin{abstract}
Earlier experimental work has attempted to account for Word Association Test response faults as being due to response entropy, thereby discounting emotional disturbance as an explanatory variable. The present study demonstrates that response entropy is a function of the emotional connotation of the stimulus word, for both college and schizophrenic Ss, and that this affective variable is more important than stimulus familiarity in determining the response variability.
\end{abstract}

\section{Problem}

Responses to the word association test have become the basis for a large number of studies of verbal behavior. Although emphasis was initially focused on the most popular responses given, investigators have subsequently found it important to describe the nature of the entire response distribution (Garskof \& Houston, 1963; Horvath, 1963). Laffal made an early contribution to this problem with his paper on the relationship between response faults and response entropy. He demonstrated that the occurrence of a lengthy reaction time and/or reproduction errors were related to the number of different responses given to that stimulus word. From this finding he concluded that these response faults on a word-association test were due to the nature of the response distribution. This conclusion stood in opposition to the common clinical assumption that response faults are indicators of emotional disturbance (Jung, 1919; Rapaport, 1946).

While Laffal's study pointed out the importance of knowing the characteristics of the distibution of responses, it does not seem completely warranted to rule out the role of emotional factors as influencing response processes. If response faults are more likely to occur to stimuli which elicit a greater number of different responses, it then becomes important to determine why some stimuli elicit so many more responses than others; we are still left with the question of what factors determine the size of the associative domain. It is one thesis of the present paper that the emotional connotation of the stimulus word is an important factor in determining the number of different responses elicited by that stimulus. More specifically, it is hypothesized that Traumatic stimulus words will elicit a greater number of different responses than will Neutral stimuli.

Another variable which should be considered as a possible determinant of response variability is that of familiarity, or frequency of usage, of the stimulus word. Both Cofer \& Shevitz (1952) and Terwillinger (1964) have demonstrated that words of high Thorndike-Lorge frequency elicit more different responses. Other studies, however, raise some doubt about the importance of stimulus familiarity, and suggest that personality variables (Davids, 1956) or affective quality of the stimulus (Deering, 1963; Terwillinger, 1964) may be more important factors. In the light of these inconclusive findings, a second hypothesis of the present study is that stimulus familiarity will be less important in determining response variability than will the emotional connotation of the stimulus word.

\section{Experiment 1}

\section{Method}

Following standard instructions, a written word association test was adminstered to 167 students (43 male, 124 female) of college pshychology. The test consisted of 20 Traumatic and 40 Neutral stimulus words (see Rapaport, 1946), and was given in group fashion.

\section{Results ${ }^{3}$}

The number of different responses given to each stimulus word was determined for both Traumatic and Neutral stimuli. This simpler measure of response dispersion was used in place of the more complicated entropy measure $\left(\mathrm{H}=-\mathrm{p}_{\mathrm{i}} \log _{2} \mathrm{p}_{\mathrm{i}}\right)$, following Laffal's finding that 'D is a more reliable measure of the response hierarchy than is $H^{\prime \prime}(1955$, p. 268).

The results indicated that the mean number of different responses given to Traumatic stimuli $(\bar{X}=43.85$, S.D.=12.79) was significantly greater than that obtained to Neutral stimuli $\left(\overline{\mathrm{X}}=34.21, \mathrm{~S}_{\circ} \mathrm{D} .=11.78\right)(\mathrm{t}=\mathbf{2 . 8 4}$, $\mathrm{p}<.01)$.

For purposes of determining the relationship of stimulus familiarity to number of different responses, the stimulus words were divided into two frequency categories. One category consisted of words occurring at least 50 times per million (Thorndike-Lorge rating of $\mathrm{AA}$ and $\mathrm{A})$; the other category consisted of words occurring less than 50 per million. Stimulus words which were so rare as not to appear in the ThorndikeLorge list were assigned to this latter category.

The mean number of responses elicited by frequent and infrequent words was quite similar (37.89 and 36.83 , respectively); a $t$ test was insignificant $(t=.31)$. A bi-serial $r$ of +.06 also demonstrated the absence of a significant relationship between the two variables.

\section{Experiment 2}

Data for responses to the same word association test was obtained for 200 psychiatric patients ( 107 male, 93 female), all with a diagnosis of schizophrenia. 
The patients were tested individually as part of a standard psychological evaluation.

\section{Results ${ }^{3}$}

Again, Traumatic stimulus words elicited significantly more different responses than did Neutral words (Traumatic $\overline{\mathrm{X}}=72.95$, S.D. $=20.97$; Neutral $\overline{\mathrm{X}}=61.60$, S.D. $=16.00 ; t=2.32, p<.025)$.

For this $\mathrm{S}$ group, the infrequent, or unfamiliar stimulus words elicited a somewhat greater number of different responses than the frequent stimuli (70.61 vs. 62.14 , respectively), but the difference did not reach an acceptable level of significance $(t=1.76, p=.087)$. The corresponding bi-serial $r$ of -.22 was also insignificant.

\section{Diseussion}

The present findings clearly support the hypothesis that the affective quality of a stimulus word determines the number of different responses elicited by that word. For both college students and schizophrenic patients, stimulus words which were previously designated as Traumatic elicited many more different responses than did words designated as Neutral. Furthermore, the results showed that the emotional connotations of the stimulus words were more important than stimulus familiarity in determining response variability. The Thorndike-Lorge frequency of the stimulus was not significantly related to number of different responses, for either $\mathrm{S}$ group.

Considering these data, it would seem that the earlier formulation that response faults are a function of response entropy (Laffal, 1955) must be expanded to include the idea that entropy, in turn, is a function of the affective quality of the stimulus. When the (negative) emotional connotation of stimuli is increased, the associative hierarchies become less well organized and more diffuse. It is further suggested that this kind of response dispersion may be related to the de-differentiation, or overinclusiveness, which characterizes certain forms of pathological thinking.

\section{References}

Cofer, C. N., \& Shevitz, R. Word-association as a function of word frequency. Amer. J. Psychol., 1952, 65, 75-79.

Davids, A. Personality dispositions, word frequency, and word association. J. Pers., 1956, 24, 328-338.

Deering, Gayle. Affective stimuli and disturbance of thought processes. J. consult. Psychol., 1963, 27, 338-343.

Garskof, B. E., \& Houston, J. P. Measurement of verbal relatedness: an idiographic approach. Psychol. Rev., 1963, 70, 277-288.

Horvath, W. J. A stochastic model for word association tests. Psychol. Rev., 1963, 70, 361-364.

Jung. C. G. Studies in word association. New York: Moffat, Yard, 1919

Laffal, J. Response faults in word association as a function of response entropy. J. abnorm. soc. Psychol., 1955, 50, 265-270.

Rapaport. D., Gill, M., \& Schafer, R. Diagnostic psychological testing. Vol. II. Chicago: Year Book Publishers, 1946.

Terwillinger, R. F. Free association patterns and familiarity as predictors of affect. J. gen. Psychol., 1964, 70, 3-12.

\section{Notes}

1. This research was supported in part by small grant MH 10504-01 from the National Institute of Mental Health, U. S. Public Health Service, and in part by Barnard College, Columbia University and the Austen Riggs Center.

2. Currently at the Institute of Human Learning, University of California.

3. Word association norms for college or patient population are available on request. 